\title{
Atmosferik Sınır Tabakası Stabilitesinin Bina Yüzey Sıcaklığı Üzerindeki Etkisi
}

\author{
Yiğit C. Altan ${ }^{11}$ \\ 1 Özyeğin Üniversitesi, Mühendislik Fakültesi, İnşaat Mühendisliği Bölümü, İstanbul, Türkiye (ORCID: 0000-0003-0208-6867)
}

(International Symposium on Multidisciplinary Studies and Innovative Technologies (ISMSIT) 2020 - 22-24 October 2020)

(DOI: 10.31590 /ejosat.821743)

ATIF/REFERENCE: Altan, Y. C. (2020). Atmosferik Sınır Tabakası Stabilitesinin Bina Yüzey Sıcaklığı Üzerindeki Etkisi. Avrupa Bilim ve Teknoloji Dergisi, (Özel Sayı), 264-269.

\section{$\ddot{\mathbf{O} z}$}

Net sıfir enerjili binalar, insanlığın enerji tüketimini azaltmaya yönelik en önemli adımlardan biridir. Binalarda, önemli miktarda enerji ısıtma ve soğutma amacıyla kullanılmaktadır. Binalarda atmosfer ile 1sı transferi yüzeyleri vasıtasıyla gerçekleşmektedir. Bina yüzeyinin dışı ve içerisi arasındaki fark duvarlardan iletilecek ısı miktarını belirlemektedir. Bina dış yüzeyinin sıcaklı̆̆ı rüzgar, güneş radyasyonu, dış sıcaklık ve Atmosferik Sınır Tabakası (AST) stabilite özellikleri gibi çevresel koşullara göre değişebilir. HAD simülasyonları yardımıyla, bina yüzeyi sıcaklık değişimi bir 1sı haritası olarak oluşturulabilir. Oluşturulan 1sı haritası, enerji verimli binaların tasarlanmasına yardımcı olabilir.

Bu çalşşmada, genel bir binanın cephe sıcaklık haritası ANSYS Fluent ile simüle edilmiş̧ir. AST'nin tabakalaşması türbülans özelliklerini ve dikey profildeki sıcaklığı değiştirdiğinden, simülasyonlar sırasında tabakalaşmaya özel önem verilmektedir. MoninObukhov (M-O) uzunluğuna göre farklı tabakalaşma seviyeleri belirlenir. Simülasyonlar için RANS denklemleri çözülmüş ve türbülans modellemesi için realizable k- $\varepsilon$ modeli kullanılmıştır. Simülasyon için giriş, çıkış ve alt kısımdaki sınır koşulları M-O benzerliği doğrultusunda verilmiştir. Tam boyutlarıyla modellenen binaya literatürden alınan 1sı akışı değerleri verilmiş̧ir. Üç farklı rüzgar hızı ve üç farklı tabakalaşma durumu analiz edilerek sonuç olarak 9 senaryo oluşturulmuştur. Oluşturulan senaryoların hepsinde yer seviyesi sıcaklık 27 derece olarak alınmış ve binaların ürettiği 1 sı akışı $105 \mathrm{w} / \mathrm{m}^{2}$ olarak literatürden alınmıştır. 9 senaryonun sonucu karşılaştıııldığında, tabakalaşmanın binanın cephe sıcaklığı üzerindeki etkisi gözlemlenmiştir. Rüzgar hızı arttıkça, tabakalaşmanın cephe sıcaklığı üzerindeki etkisi artmaktadır.

Anahtar Kelimeler: Bina yüzey sıcaklığı, Atmosferik sınır tabakası, Bina Enerji Simülasyonu (BES), Katmanlaşmış akış, Hesaplamalı Akışkanlar Dinamiği (HAD), Reynold Averaged Navier-Stokes (RANS).

\section{The Effect of Atmospheric Boundary Layer Stratification on the Facade Temperature}

\begin{abstract}
The net-zero energy buildings are one of the most important steps towards decreasing the total energy consumption of humanity. In the buildings, a considerable amount of energy is used for heating and cooling purposes, and heat is transferred to the atmosphere via the façade of the buildings. The difference between the inside and outside temperature of the facade determine the heat flux through the walls. The temperature of the façade can vary with environmental conditions such as wind, solar radiation, outside temperature, and stability characteristics of the Atmospheric Boundary Layer (ABL). With the aid of CFD simulations, the temperature variation can be created as a heat map. The created heat map can help to design energy-efficient buildings.
\end{abstract}

\footnotetext{
${ }^{1}$ Sorumlu Yazar: Özyeğin Üniversitesi, Mühendislik Fakültesi, İnşaat Mühendisliği Bölümü, İstanbul, Türkiye, ORCID: 0000-0003-0208-6867, yigitcan.altan@ozyegin.edu.tr
} 
In this study, the façade temperature map of a generic building is simulated with ANSYS Fluent. Since the stratification changes the turbulence characteristics and temperature along with the vertical profile of $\mathrm{ABL}$, special care is given to the stratification during the simulations. Different stratification levels are determined in line with the Monin-Obukhov (M-O) length. For the simulations, RANS equations are solved and the realizable $\mathrm{k}-\varepsilon$ model is used for the turbulence modeling. The boundary conditions at the inlet, outlet, and bottom are given in line with the M-O length. The building is explicitly modeled and heat flux values taken from the literature. Three different wind speed and three different stratification conditions are analyzed and as a result, 9 scenarios are created. The result of the 9 scenarios shows the effect of stratification on the facade temperature of the building. As the wind speed increases the effect of stratification on the facade temperature increases.

Keywords: Building facade temperature, Atmospheric boundary layer, Building Energy Simulation (BES), stratified flow, Computational Fluid Dynamics (CFD), Reynold Averaged Navier-Stokes (RANS).

\section{Giriş}

İklim değişikliği etkilerini azaltmak ve doğayla uyumlu yaşamak üzere Avrupa Birliği yaptığı düzenlemeler ile 2030'dan itibaren yeni yapılan bütün binaların ve 2050 yılına kadar da mevcut bina stokunun sıfır enerji tüketimli binalar olmasını hedeflemiştir (Sartori, Napolitano, \& Voss, 2012). Bu hedefler doğrultusunda binaların enerji verimliliğini arttırmanın önemi ön plana çıkmıştır. Bu hedefi gerçekleştirmek için yapılacak planlamaların başında da Bina Enerji Simülasyonları (BES) gelmektedir. BES, daha proje aşamasında iken binanın enerji tüketimi hakkında fikir verebilmekte ve projede doğru yönde değişiklikler yapılabilmesini sağlamaktadır (Önal, 2014). BEP modellerinin sağlıklı sonuçlar verebilmesi dış ve iç koşul girdilerinin gerçekçiliği ile doğru orantılıdır. İç koşullar daha çok binanın kullanımı ile ilgili iken, dış koşullar binanın dış yüzeyinin maruz kaldığı sıcaklık, rüzgar vb. gibi çevresel koşullar ile ilintilidir. Bu çalışmada odağında dış koşullardan olan hava sıcaklığının ve rüzgarın bina yüzey sıcaklığı üzerindeki etkisi ele alınmaktadır.

Binaların çevresindeki hava akışı ve sıcaklık dağılımı Hesaplamalı Akışkanlar Dinamiği (HAD) ile başarı ile modellenebilmektedir (Allegrini, Dorer, \& Carmeliet, 2015; Bartak et al., 2002; Hosseini, Tardy, \& Lee, 2018). Bu modellemeler 1şı̆̆ında bina yüzeyindeki sıcaklık farklarının binaların ısı performansı üzerindeki etkileri açığa çıkartılmıştır. Ayrıca binaların yapı malzemelerinden kaynaklanan 1S1 kapasiteleri, çevresinin sıcaklığını değiştirmekte ve 1S1 adalarının açığa çıkmasına sebep olmaktadır (Oke, 1973). Bu 1S1 adaları kaldırma etkili akışları desteklemekte ve binalar arasındaki hava akışlarını değiştirmektedir (Allegrini, Dorer, \& Carmeliet, 2014; Xie, Liu, Leung, \& Leung, 2006). Ancak binaların içinde bulunduğu ve yaşam faaliyetlerinin sürdüğü Atmosferik Sınır Tabakası (AST) her zaman için aynı özellikleri göstermemektedir (Panofsky \& Dutton, 1984).

AST yapısındaki değişikliklerin başında katmanlaşma vardır. Katmanlaşma hava yoğunluğunun yer seviyesinden yukarı doğru artması durumunda kararsız katmanlaşma ve azalması durumunda ise kararlı katmanlaşma olarak isimlendirilmektedir. Kararlı katmanlaşma havanın türbülans karakteristiğinde değişikliklere yol açmakta (Mahrt, 1999) ve binaları doğrudan etkilemektedir. İklim değişikliği ile beraber kararlı katmanlaşma ile ilintili olan 1sı dalgaları (Miralles, Teuling, Van Heerwaarden, \& De Arellano, 2014) sayısı artmakta ve sağlıklı BES çıktıları için incelenmesi önem arz etmektedir.

Katmanlaşma Monin-Obukhov benzerliği ile açıklanmakta ve katmanlaşmanın şiddeti M-O uzunluğu (L) ile gösterilmektedir (Monin \& Obukhov, 1954). Kararlı katmanlaşma değerli pozitif, kararsız katmanlaşama değerleri negatif rakamlarla gösterilir ve 0'a yaklaştıkça katmanlaşmanın şiddeti artmaktadır. Kararlı katmanlaşmanın şiddeti arttıkça türbülans karakteristiği zayıflamaktadır (Mahrt, 1998). Bu çalışmada L100 kararlı, L250 az kararlı ve L500 natüral koşulları üç farklı rüzgar hızı ile simüle edilerek katmanlaşmanın bina yüzeyi sıcaklığı üzerindeki etkisi incelenmiştir.

\section{Metot}

Bina yüzey sıcaklığının dış koşullara göre simülasyonu için ANSYS Fluent (2020R2) programı kullanılmıştır. Simülasyonda 85m x 40m x 35m (U x G x Y) boyutlarında bir bina modellenmiştir. Şekilde 1'de gösterildiği gibi simülasyon alanı her bir kenarı 500 metre olan bir sekizgen olarak modellenmiş ve bina bu alanın tam ortasına konumlanmıştır. Simülasyonun ana hedefi bina yüzey sıcaklığının daha iyi çözümlenmesi olduğu için Şekil 2'de gözüken biçimde bina çevresindeki mesh yoğunluğu şişme tabakası ile arttırılmıştır. Bu tabakada en küçük katman $10 \mathrm{~cm}$ olarak alınmış ve 1,1 katsayısı ile artacak şekilde 50 katman oluşturulmuştur. Bu meshleme sonucunda bütün simülasyon alanı toplam olarak 1.623 .328 hücreye bölünmüştür. 


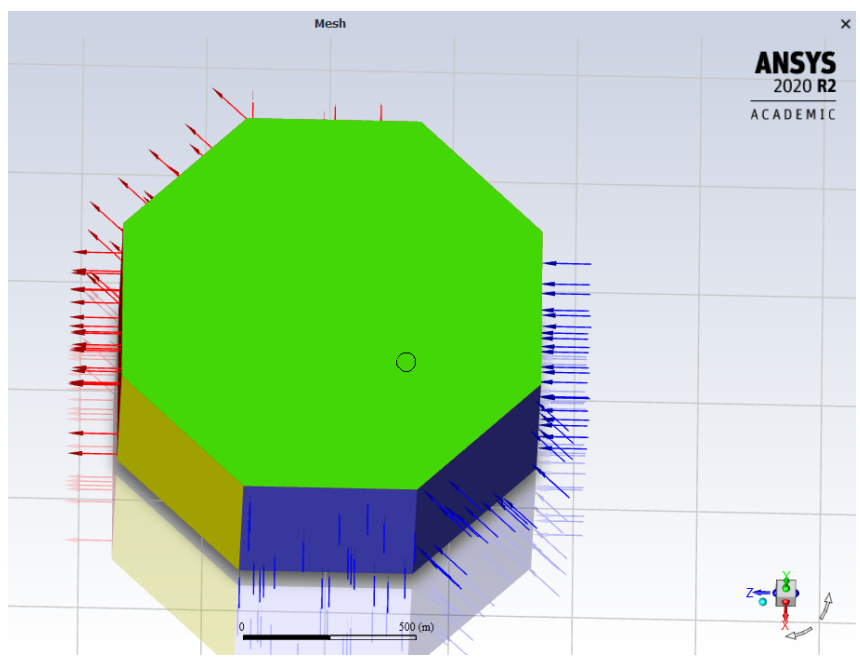

Şekil 1. Simülasyon alanı

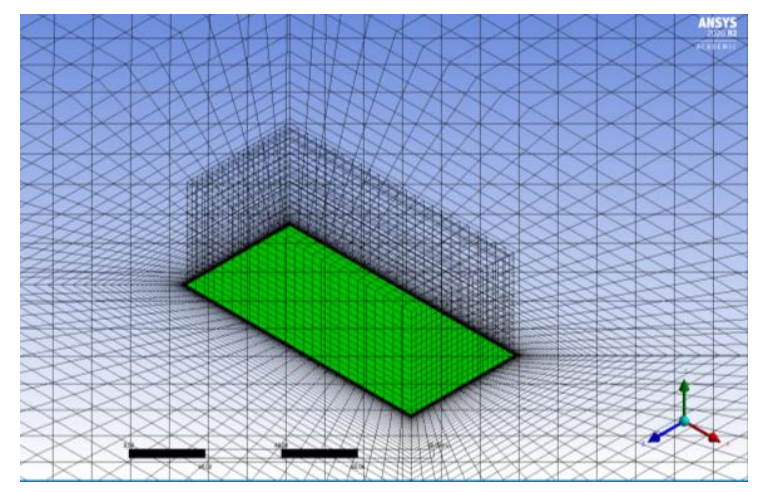

Şekil 2. Bina çevresi meshleme

Bina yüzey sıcaklıklarının çözümünde Navier-Stokes ve enerji denklemleri akuple edilerek ANSYS Fluent ile çözümlenmiştir. Navier-Stokes denklemlerinde RANS denklemleri kullanılmış ve türbülans denklemlerinin modellenmesinde kaba cisim aerodinamiği ile daha uyumlu olan realizable $k-\varepsilon$ denklemleri kullanılmıştır. Sıcaklık ile değişen sıvı yoğunluğunu çözümlemek için hava sıkıştırılmaz ideal gaz olarak modellenmiştir.

Rüzgar profili belirlenirken M-O uzunluğu (L) kullanılmıştır. Bu uzunluk, denklem 1'de gösterildiği gibi hesaplanmaktadır.

$$
L=\frac{\rho C_{p} u_{*}^{3} \theta_{0}}{\kappa g \theta_{*}}
$$

burada,

$L$, Monin-Obukhov uzunluğu (m)

$\rho$, havanın yoğunluğu

$C_{p}$, havanın spesifik 1sı kapasitesi

$\theta$, yer seviyesindeki potansiyel sicaklık (K)

$g$, yerçekim ivmesi $\left(\mathrm{m}^{2} / \mathrm{s}\right)$

$\theta_{*}$, birimsiz sıcaklık skalası ve denklem 2'deki gibi hesaplanmaktadır.

$$
\theta_{*}=\frac{-H}{\rho C_{p} u_{*}}
$$

burada,

$H, 1 \mathrm{~s} 1$ akışı $\left(\mathrm{w} / \mathrm{m}^{2}\right)$ 
M-O uzunluğuna göre belirlenen rüzgar profili ve sıcaklık denklem 3 ve 4'de gösterilmektedir.

$$
\begin{gathered}
U(z)=\frac{u_{*}}{k}\left[\ln \left(\frac{z}{z_{0}}\right)-\Psi_{m}\left(\frac{z}{L}\right)\right] \\
\theta(z)=\theta_{\text {base }}+\frac{\theta_{*}}{k}\left[\ln \left(\frac{z}{z_{0}}\right)-\Psi_{h}\left(\frac{z}{L}\right)\right]
\end{gathered}
$$

burada,

$$
\Psi_{m}=\Psi_{h}=-5 \frac{z}{L}
$$

Rüzgar ve sıcaklık profilini simülasyon alanı içerisinde düzgün şekilde koruyabilmek için duvar fonksiyonları kullanılmıştır.

$$
k_{S}=\frac{9.793 z_{0} \exp \left(\Psi_{m}\left(\frac{y_{p}}{L}\right)\right)}{C_{S}}
$$

burada ,

$y_{p}$, yere temas eden hücrenin orta yüksekliğidir.

Hava akışının ilk temasının iki cephe ile olmasını sağlamak amacıyla rüzgar yönü bina ile 45 derece açı yapacak şekilde seçilmiştir.

\begin{tabular}{|c|c|c|c|c|}
\hline & \multicolumn{3}{|c|}{$\begin{array}{c}\text { Rüzgar Hızı } \\
\text { Referans yüksekliği }=50 \mathrm{~m}\end{array}$} \\
\hline & & $2,5 \mathrm{~m} / \mathrm{s}$ & $5 \mathrm{~m} / \mathrm{s}$ & $7,5 \mathrm{~m} / \mathrm{s}$ \\
\hline \multirow{3}{*}{ 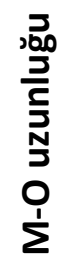 } & L 100 & 1 & 2 & 3 \\
\hline & L 250 & 4 & 5 & 6 \\
\hline & L 500 & 7 & 8 & 9 \\
\hline
\end{tabular}
Kullanılan rüzgar hızları, katmanlaşma değerleri ve bu kombinasyona karşıllk gelen simülasyon numaraları Tablo 1'de verilmiştir. Yaratılan 9 senaryoda da yer seviyesi sıcaklığı 27 derece olarak kabul edilmişsir.

Tablo 1. Rüzgar ve katmanlaşma koşulları ve karşılık gelen senaryo numaraları

\section{Araştırma Sonuçları ve Tartışma}

Bu çalışmada 3 farklı rüzgar ve 3 farklı katmanlaşma koşulunun kombinasyonu olarak 9 farklı simülasyon yapılmıştır ve binaların yüzey sıcaklık haritaları çıkartılmıştır. Simüle edilen binalarda $105 \mathrm{w} / \mathrm{m}^{2}{ }^{\prime}$ lik bir 1 sı akışı sağlanmış ve bu sayede tekil bir binanın yaydığı 1s1 modellenmiş olmuştur (Allen, Lindberg, \& Grimmond, 2011). Simülasyonlardaki temel amaç tabakalaşmanın binanın yüzey sicaklığ1 üzerindeki etkisini çıkarmak olduğu için simülasyon sonuçları buna göre gruplanmıştır.

1,2 ve 3 numaralı simülasyonlar çok düşük rüzgar hızı olarak kabul edilen 2,5m/s için gerçekleştirilmiştir. Bu senaryolardaki ana değişken AST'nin kararlılık derecesidir. Şekil 3. de gözüktüğü gibi bina yüzey sıcaklıklarında farklılıklar gözlemlenmektedir. Bu farklılıklar özellikle rüzgaraltı genişlik (güney) ve rüzgarüstü uzunluk (batı) cephelerinde gözlemlenmektedir. 


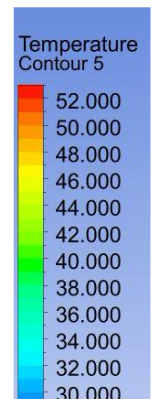

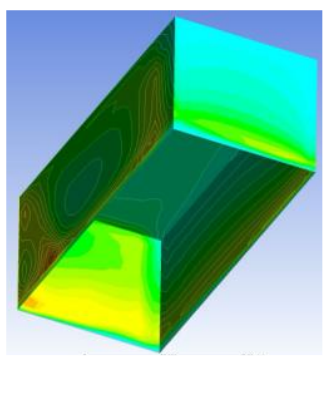

L 100 (1)

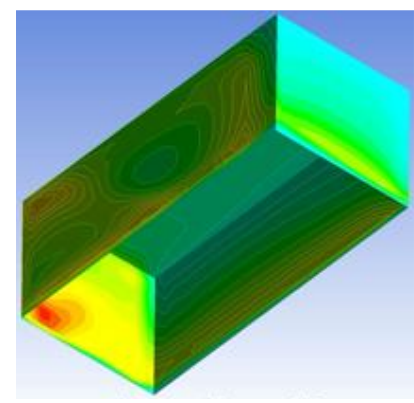

L 250 (2)

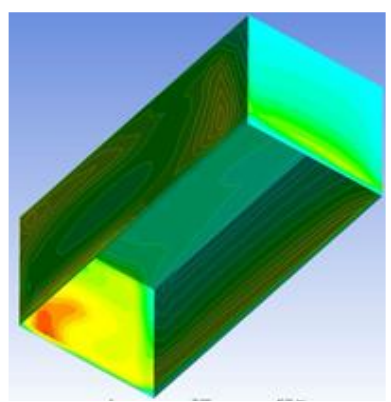

L 500 (3)

Şekil 3.

4,5 ve 6 numaralı simülasyonlar düşük rüzgar hızı olarak kabul edilen $5 \mathrm{~m} / \mathrm{s}$ için gerçekleştirilmiştir. Natürele yakın koşul olan simülasyon 6'da rüzgaraltı tarafta tabana yakın yerlerde daha yüksek sıcaklıklar gözlemlenirken, yükseklik ile beraber yüzey sıcaklıkları stabil koşulların altına düşmektedir.

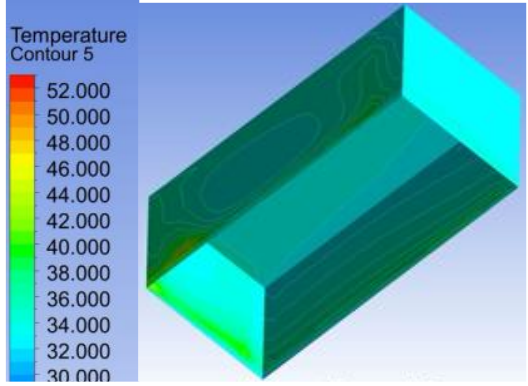

L 100 (4)

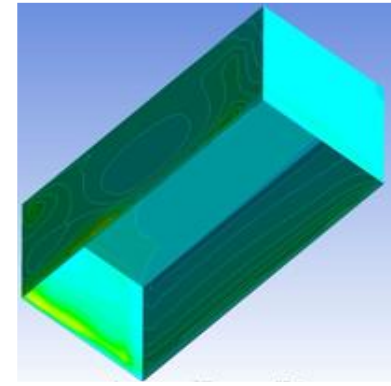

L 250 (5)

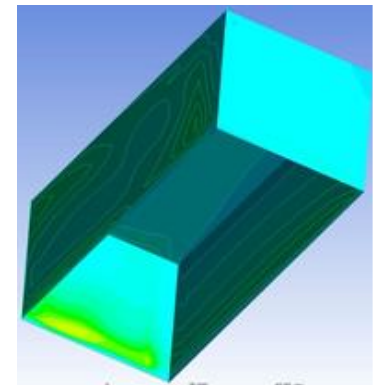

L 500 (6)

Şekil 4.

7, 8 ve 9 numaralı simülasyonlar normal rüzgar hızı olan 7,5 m/s koşulu için gerçekleştirilmiştir. Şekil 5'de verilen sonuçlara göre binaların yüzey sıcaklıkları artan rüzgarın etkisi ile düşmek ile beraber senaryo 7 ve 8 'de diğer senaryoya kıyasla genel olarak daha sıcak bir yüzey gözlemlenmektedir.
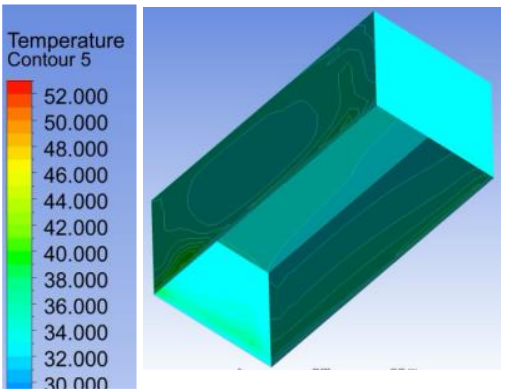

L 100 (7)

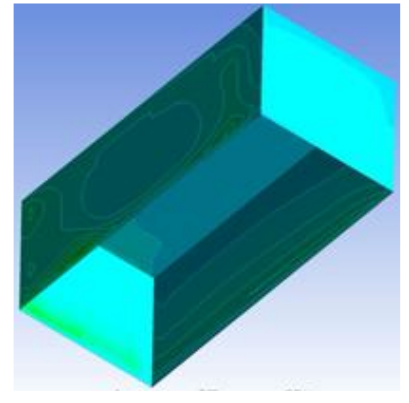

L 250 (8)

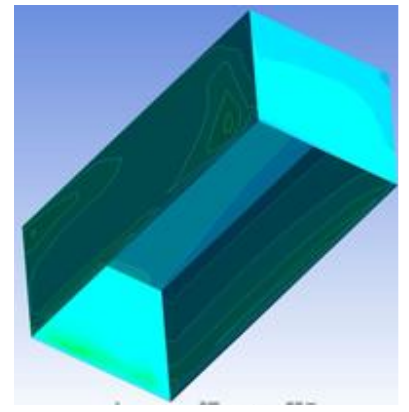

L 500 (9)

Şekil 5.

Şekil 3, 4 ve 5 deki yüzey haritaları detaylı karşılaştırma ve alınacak önlemler için çok önemli olsa da yüzeylerin ortalama sıcaklıları genel bir karşılaştırma şansı vermektedir. Bu bağlamda yüzeylerin ortalama sıcaklıkları Tablo 2'de verilmiştir. Bu sonuçlar, katmanlaşmış koşullarda (L100 ve L250) bina yüzey sıcaklığının arttığını daha açık şekilde göstermektedir. Ayrıca rüzgar hızı arttıkça katmanlaşmanın etkisi artmakta ve senaryo 7 ve 8'deki yüzey sıcaklıkları senaryo 9'a göre önemli farklılıklar göstermeye başlamaktadır. Bu sıcaklık farkının ana nedeni rüzgar hızıyla katmanlaşmanın türbülans üzerindeki etkisinin daha açıkça hissedilmesi ve rüzgar ile 1sı iletiminin azalmasıdır. 
Tablo 2. Koşullara göre yüzey sıcaklık değerleri

\begin{tabular}{|c|c|c|c|c|c|c|c|c|c|c|}
\hline & \multirow{2}{*}{\begin{tabular}{|l|} 
rüzgar hızı $(\mathrm{m} / \mathrm{s})$ \\
M-O uzunluğu \\
\end{tabular}} & \multicolumn{3}{|c|}{2.5} & \multicolumn{3}{|c|}{5} & \multicolumn{3}{|c|}{7.5} \\
\hline & & L100 & L250 & L500 & L100 & L250 & L500 & L100 & L250 & L500 \\
\hline \multirow{8}{*}{ Sicaklık $\left({ }^{\circ} \mathrm{C}\right)$} & çatı & 36.6 & 36.99 & 36.46 & 33.23 & 32.89 & 32.41 & 33.17 & 31.89 & 31.26 \\
\hline & kuzey (rüzgarüstü genişlik) & 36.81 & 37.42 & 36.99 & 33.21 & 33.02 & 32.65 & 33.04 & 31.93 & 31.39 \\
\hline & batı (rüzgarüstü uzunluk) & 38.72 & 39.17 & 38.57 & 34.27 & 34.01 & 33.49 & 33.78 & 32.62 & 31.97 \\
\hline & güney (rüzgaraltı genişlik) & 42.09 & 44.51 & 44.4 & 36.12 & 36.82 & 36.63 & 35.09 & 34.66 & 34.13 \\
\hline & doğu (rüzgaraltı uzunluk) & 40.99 & 42.2 & 40.83 & 35.22 & 35.54 & 34.84 & 34.44 & 33.66 & 32.93 \\
\hline & yüzeylerin min & 36.6 & 36.99 & 36.46 & 33.21 & 32.89 & 32.41 & 33.04 & 31.89 & 31.26 \\
\hline & yüzeylerin max & 42.09 & 44.51 & 44.4 & 36.12 & 36.82 & 36.63 & 35.09 & 34.66 & 34.13 \\
\hline & ortalama & 39.04 & 40.06 & 39.45 & 34.41 & 34.46 & 34.00 & 33.90 & 32.95 & 32.34 \\
\hline
\end{tabular}

\section{Sonuç}

Bu çalışmada 9 farklı koşul için bina yüzey sıcaklıkları bulunmuş ve katmanlaşmanın bina yüzey sıcaklığı üzerindeki etkisi araştırılmıştır. HAD ile yapılan simülasyonların çözümlemeler için ANSYS Fluent programı kullanılmıştır.

Yapılan 9 farklı simülasyon 1şığında katmanlaşmanın bina yüzey sıcaklığı üzerinde etkisi olduğu ortaya konmuştur. Bu etkinin rüzgar hızı arttıkça arttığı gözlemlenmiştir. Bunun en önemli nedeni olarak rüzgar hızı arttıkça, türbülans karakteristiğindeki değişimlerin daha fazla açığa çıkmasıdır. Bunlara ilaveten, üretilen bina sıcaklık haritaları bir bina üzerinde çok farklı sıcaklığın bulunabileceğini göstermiştir ve binaların 1sı performansı için HAD simülasyonlarının önemi göstermiştir. Özellikle büyük binalarda bu sıcaklık değişimleri göz önüne alınarak yapılacak yalıtım çalışmaları ile daha yüksek bir yalıtım/maliyet performansı yakalanabilir ve kaynakların daha etkili kullanılması sağlanabilir.

Yapılan çalışmadan elde edilen dikkate değer sonuçlar bu alanda daha detaylı çalışmalar yapılması gerektiğini göstermektedir. Bu çalışmayı kanopi model ile destekleyerek bina sıralarının sıcaklık haritalarının bulunması ve 1sı adası etkisinin incelenmesi gerçek şehirleşme koşulları hakkında daha derinlemesine bilgi sahibi olmamızı sağlayacaktır. Ayrıca, kanopi simülasyonlarına eklenecek güneş ışıması etkisi hem gölgelenme etkisini de inceleyerek günlük koşullara yaklaşmamızı sağlayacaktır. Yılın tamamını kapsayan koşullar yaratmak için daha fazla senaryo üzerinde çalışılması, ileride yapılacak binalar için bir kılavuz oluşturulmasına yardımcı olacaktır.

\section{Kaynakça}

Allegrini, J., Dorer, V., \& Carmeliet, J. (2014). Buoyant flows in street canyons: Validation of CFD simulations with wind tunnel measurements. Building and Environment, 72, 63-74. https://doi.org/10.1016/j.buildenv.2013.10.021

Allegrini, J., Dorer, V., \& Carmeliet, J. (2015). Coupled CFD, radiation and building energy model for studying heat fluxes in an urban environment with generic building configurations. Sustainable Cities and Society, 19, 385-394. https://doi.org/10.1016/j.scs.2015.07.009

Allen, L., Lindberg, F., \& Grimmond, C. S. B. (2011). Global to city scale urban anthropogenic heat flux: Model and variability. International Journal of Climatology, 31(13), 1990-2005. https://doi.org/10.1002/joc.2210

Bartak, M., Beausoleil-Morrison, I., Clarke, J. A., Denev, J., Drkal, F., Lain, M., ... Stankov, P. (2002). Integrating CFD and building simulation. Building and Environment, 37(8-9), 865-871. https://doi.org/10.1016/S0360-1323(02)00045-8

Hosseini, M., Tardy, F., \& Lee, B. (2018). Cooling and heating energy performance of a building with a variety of roof designs; the effects of future weather data in a cold climate. Journal of Building Engineering, 17(February), 107-114. https://doi.org/10.1016/j.jobe.2018.02.001

Mahrt, L. (1998). Stratified Atmospheric Boundary Layers and Breakdown of Models. Theoretical and Computational Fluid Dynamics, 11(3-4), 263-279. https://doi.org/10.1007/s001620050093

Mahrt, L. (1999). Stratified atmospheric boundary layers. Boundary-Layer Meteorology, 90(3), 375-396. https://doi.org/10.1023/A:1001765727956

Miralles, D. G., Teuling, A. J., Van Heerwaarden, C. C., \& De Arellano, J. V. G. (2014). Mega-heatwave temperatures due to combined soil desiccation and atmospheric heat accumulation. Nature Geoscience, 7(5), 345-349. https://doi.org/10.1038/ngeo2141

Monin, A. S., \& Obukhov, A. M. (1954). Basic laws of turbulent mixing in the surface layer of the atmosphere. Contrib. Geophys. Inst. Acad. Sci. USSR, 24(151), 163-187.

Oke, T. R. (1973). City size and the urban heat island. Atmospheric Environment Pergamon Pres, 7, 769-779. https://doi.org/10.1016/0004-6981(73)90140-6

Önal, S. (2014). Yapıların Enerji Kimlik Belgeleri Üzerine Değerlendirmeler Evaluation on Energy Identity Documents of The Buildings. European Journal of Science and Technology, 1(3), 100-105.

Panofsky, H. A., \& Dutton, J. A. (1984). Hans A Panofsky_John A Dutton -Atmospheric turbulence _ models and methods for engineering applications-Wiley (1984).pdf. Newyork: Wiley - interscience.

Sartori, I., Napolitano, A., \& Voss, K. (2012). Net zero energy buildings: A consistent definition framework. Energy and Buildings, 48, 220-232. https://doi.org/10.1016/j.enbuild.2012.01.032

Xie, X., Liu, C. H., Leung, D. Y. C., \& Leung, M. K. H. (2006). Characteristics of air exchange in a street canyon with ground heating. Atmospheric Environment, 40(33), 6396-6409. https://doi.org/10.1016/j.atmosenv.2006.05.050 